\title{
Aerobic Oxidation of $\beta$-Isophorone by Tetraphenylporphyrin Catalysts in Pyridine Solution
}

Eric Burns ${ }^{1}$, Tao Huang ${ }^{1}$, Walter W. Weare ${ }^{1}$, Libero Bartolotti ${ }^{2}$, Xinyu Wang ${ }^{3}$, Jia Yao $^{3}$, Haoran Li $^{3 *}$, Stefan Franzen $^{1,3^{*}}$

1. Department of Chemistry, North Carolina State University, Raleigh, NC, 27695 USA

2. Department of Chemistry, East Carolina University, Greenville, NC, 27858 USA

3. Department of Chemistry, Zhejiang University, Zheda Road, Hangzhou, China 310027

*Authors to whom correspondence should be addressed:

Dr. Stefan Franzen

Department of Chemistry

North Carolina State University

Raleigh, NC 27695

Phone: 1(919)5158915

Fax: 1(919)5158920

Email: franzen@ncsu.edu

Dr. Haoran Li

Department of Chemistry

Zhejiang University

Hangzhou, China 310027

Phone: 86(571)87952424

Fax: 86(571)87951895

Email: $\underline{\text { lihr@zju.edu.cn }}$ 


\section{Abstract}

A kinetic study was conducted using five metallo-tetraphenylporphyrins (MTPPs) as catalysts for the aerobic oxidation reaction of $\beta$-isophorone ( $\beta$-IP) to ketoisophorone (KIP). The oxidation reaction catalyzed by MTPPs $(\mathrm{M}=\mathrm{Cr}, \mathrm{Mn}, \mathrm{Fe}, \mathrm{Co}$ and $\mathrm{Cu})$ was observed over a seven hour period under a range of experimental conditions. Changes in the specificity of conversion of reactant to the product, $\mathrm{KIP}$, and the main side-product, $\alpha$-isophorone $\left(\alpha\right.$-IP), were observed at temperatures ranging from $60{ }^{\circ} \mathrm{C}$ to $75{ }^{\circ} \mathrm{C}$, in solvents with varying compositions of pyridine and $\beta$-IP, with different MTPP catalysts, oxygen gas flow rates, and solution agitation frequencies. Control experiments show that MTPP catalysts modestly increase the rate of KIP formation, but significantly improve specificity through the apparent suppression of $\alpha$-IP formation. Analysis revealed that $\mathrm{MnTPP}\left(\mathrm{CH}_{3} \mathrm{COO}^{-}\right)$produced the highest product specificity ratio $[\mathrm{KIP}] /[\alpha-\mathrm{IP}]$. Given that all of the metals were in the $3+$ oxidation state in this study and there was no observed binding by $\mathrm{O}_{2}$ to any of the MTPP catalysts, the catalytic mechanism is suggested to involve the binding of $\beta$-IP to the MTPP metal center. Binding of $\beta$-IP is most favorable when pyridine is the trans ligand, but $\beta$-IP is also observed to weakly bind when trans to acetate in the MnTPP adduct. This conclusion is supported by electronic absorption spectroscopy, resonance Raman spectroscopy and density functional theory (DFT) calculations. The role played by the catalyst appears to be the activation of hydrogen abstraction following the substrate's ligation to the metal, rather than the more traditional role of MTPPs as $\mathrm{O}_{2}$ activation catalysts by ligation of diatomic $\mathrm{O}_{2}$. $\beta$-IP oxidation is an example of a case where the catalyst appears to have a more important role for improving the specificity of the reaction (through decreasing sideproduct formation) rather than increasing the rate of product formation. 


\section{Introduction}

Recently, the push for more environmentally friendly or "green" chemistry has prompted exploration of oxidation by diatomic $\mathrm{O}_{2}$ in air. [1-4] Diatomic $\mathrm{O}_{2}$ is attractive because of its abundance and availability, but the limitation of the partial pressure of $\mathrm{O}_{2}$ in air requires greater emphasis on studying the catalytic mechanism in order to optimize the process. First row transition metal catalystssuch as $\mathrm{Co}, \mathrm{Mn}, \mathrm{Cr}, \mathrm{Cu}, \mathrm{Fe}$, and $\mathrm{V}$-have been extensively researched in the bonding and activation of oxygen for oxidation reactions, but systematic comparisons of their reactivity are still needed in order to understand the factors that optimize reaction rates. [5] $\mathrm{Cu}$ and Fe dominate biological oxygen chemistry and catalysis, with both being desirable from an environmental point of view as well. Clearly, many of the first tow transition elements are also abundant and environmentally compatible, which further motivates systematic study of their catalytic mechanisms.

Ketoisophorone (KIP, 3,3,5-trimethyl-cyclohex-2-ene-1,4-dione) is an important chemical intermediate used for a variety of important reactions, including vitamin E [1] and carotenoid [2] synthesis. The common precursor for KIP is isophorone, which is found in both the conjugated $\alpha$ ( $\alpha$-IP, 3,3,5-trimethyl-cyclohex-2-enone) and the unconjugated $\beta$ ( $\beta$-IP, 3,3,5-trimethyl-cyclohex-3-enone) forms. Although, $\alpha$-IP is a more readily available compound, the unconjugated isomer, $\beta$-IP is thermodynamically higher in energy and thus is more readily oxidized. Computational analysis [6] reveals significantly lower $\mathrm{C}-\mathrm{H}$ bond dissociation energies for $\beta$-IP, especially at the $\mathrm{sp}^{3}$ position of $\beta$-IP shown in Figure 1. The radical intermediate of $\beta$-IP in this position is also stabilized by $\pi$-conjugation. [5, 6 ] Since $\beta$-IP can be produced by high temperature distillation of the equilibrium mixture of $\alpha$-IP and $\beta$-IP, it is readily available as a starting material. The major obstacle to the use of $\beta$-IP from a practical point of view is the spontaneous conversion of $\beta$-IP into the thermodynamically more stable $\alpha$-IP, which is a side reaction that competes with KIP formation. The role of any catalyst for this oxidation reaction is to accelerate the formation of KIP and, perhaps more importantly, to enhance the selectivity of the reaction by increasing the ratio of $[\mathrm{KIP}] /[\alpha-\mathrm{IP}]$ in the resulting product mixture. 
The oxidation of $\beta$-IP to KIP is known using various transition metal $(\mathrm{Mn}, \mathrm{Co}, \mathrm{Cu})$ catalysts based on the ligands bissalicylaldehyde ethylenediimine (salen) [1,4] and (bis-salicylaldehyde (sal). [5] The rate equation for $\beta$-IP $\rightarrow$ KIP oxidation was determined to be rate $=\mathrm{k}[\mathrm{Cat}][\beta-\mathrm{IP}]\left[\mathrm{O}_{2}\right]^{1 / 2}$ for these systems, where Cat is the catalyst. [7] The overall reaction order according to this analysis is 2.5 over the temperature range from $10-27^{\circ} \mathrm{C}$. [1] In the present study we have focused on the role of the metal using MTPP catalysts with kinetic assays, spectroscopic studies and DFT calculations. Although $\beta$-IP is the more common starting material, several attempts have been made to synthesize KIP directly from $\alpha$-IP using catalytic radical reactions that do not involve metals. [8-11] Despite some promising results, KIP formation directly from $\alpha$-IP is slow under all conditions reported thus far. Comparative experimental data between similar $\alpha$-IP and $\beta$-IP radical oxidation reactions show that $\beta$-IP oxidation is significantly more efficient than $\alpha$-IP oxidation, with higher yields and product specificity. [6, 8] Catalysis using metal(salen) complexes show similar benefits for using $\beta$-IP over $\alpha$-IP. [12] However, some exceptions are known. For example, it has been reported that Ru(IV) tetraphenylporphyrin (TPP) efficiently catalyzes $\alpha$-IP oxidation, forming 99\% KIP after 8 hours. [13] At the present time the significant thermodynamic advantages of $\beta$-IP results in it being the only useful starting material for large-scale syntheses of KIP. Therefore, $\beta$-IP is still the main focus of mechanistic studies of KIP synthesis, with studies that utilize $\alpha$-IP remaining relatively rare. [8-10]

While elevated temperatures $\left(>110^{\circ} \mathrm{C}\right.$ ) [12] and strong oxidants (such as tert-butyl hydroperoxide) have been used for $\beta$-IP oxidation [6] [12], there has also been some progress towards the inexpensive syntheses of KIP in air using more moderate temperatures. $[8,9]$ The majority of research on $\beta$-IP oxidation is focused on catalysis by transition metal compounds in the absence of initiator. [5, 7 , $12,14]$ Thus, either $\mathrm{O}_{2}$ itself or an activated form of $\mathrm{O}_{2}$ that is bound to the catalyst must abstract a hydrogen atom to serve as the initiator for a radical mechanism. Metal tetraphenylporphyrins (MTPPs) and similar macrocyclic compounds are well known for their oxygen activation properties, $[14,15]$ but $\mathrm{O}_{2}$ can form a complex with the MTPP catalysts only if the metal is in a reduced $\left(\mathrm{M}^{2+}\right)$ state. For this reason, recent oxidation studies of related substrates catalyzed by $\mathrm{Mn}$ porphyrins have used $\mathrm{H}_{2} \mathrm{O}_{2}, \mathrm{HOCl}_{\text {or iodosylbenzene as }}$ the oxidant.[16-18] Both experimental and computational data from the present study suggest that this reduction is not favorable for either $\alpha$-IP or $\beta$-IP and therefore an alternative mechanism must be operative, which we propose involves ligation by the substrate to 
the metal of MTPP. There are other reactions by MTPPs, which produce intermediates with reactivity towards C-H bonds, such as a halogenation reaction catalyzed MnTPPCl. [19]

One attractive feature of the porphyrin scaffold is the ability to compare different metal ions in order to gain insight into the catalytic mechanism. Moreover, MTPPs have produced some of the most promising results under conditions of ambient temperature using the $\mathrm{O}_{2}$ in air as the oxidant. In particular, MnTPP [20] and Cu-DSALA [21] have been demonstrated to produce excellent yields of $93 \%$ and 95\%, respectively. However, despite the widespread use of MTPP and related compounds for the oxidation of either isomer of isophorone there remains a paucity of kinetic analyses or this class of catalytic reactions. [5]

The proposed mechanism for the oxidation of $\beta$-IP with a MTPP catalyst in air (Figure 2) can follow two possible pathways involving radical intermediates. The role of the catalyst is slightly different in both mechanisms, as is the requirement for an external base. However, both involve isomerization of the radical once formed and addition of diatomic $\mathrm{O}_{2}$ to a radical in order to form a deoxygenated intermediate. We call these two possible mechanisms the enolate-electron transfer and hydrogen abstraction mechanisms, as indicated in Figure 2.

The hydrogen abstraction mechanism (Figure 2 - right) involves immediate formation of a $\beta$-IP radical through elimination of the $\alpha$-hydrogen. In the absence of a catalyst, there is a significant yield of this product, suggesting that $\mathrm{O}_{2}$ itself can act as the oxidant for this transformation. However, in the uncatalyzed reaction isomerization to form $\alpha$-IP competes with the formation of the oxidation product resulting in poor overall yields of KIP. In this work we find that one role of the MTPP catalysts is to modestly increase the rate of KIP formation. However, we find a significant decrease in the yield of $\alpha$-IP in all cases versus the uncatalyzed reaction. The free radical IP formed by $\mathrm{H}$-abstraction in the $\alpha$ position (see Figure 2) has a resonance structure in the $\gamma$ position. Addition of $\mathrm{O}_{2}$ at the $\gamma$ position is on the pathway to form KIP, but addition of H directly forms $\alpha$-IP. In the enolate electron transfer pathway, the $\alpha$-hydrogen atom is abstracted by base (shown in Figure 2 as pyridine) to yield the enolate. If the energetics are favorable, the radical can be formed by electron transfer from the enolate to the MTPP catalyst. 
Solvents have also played a significant role in the catalyzed isophorone reaction. While there is general agreement that aprotic solvents are beneficial for the rate, $[4,5,6,21]$ pyridine has been shown to be the optimum solvent for the reaction [4, 21] despite the fact that it is known to reduce selectivity for KIP formation in other reactions. [5, 21] Unfortunately, a role for solvent has not been explained in previous studies. One important consequence of the oxidation of $\beta$-IP (or $\alpha$-IP) with $\mathrm{O}_{2}$ is the generation of stoichiometric $\mathrm{H}_{2} \mathrm{O}$, which results in a change in solvent polarity during the course of the reaction. This significant change in solvation and acid-base chemistry should be considered in the explanation of the observed kinetic profile. Our goal in this study is to identify a probable mechanism for catalytic activation that explains the relative reactivity of the series of metals studied in MTPPs.

\section{Experimental}

\subsection{Materials}

Commercial-grade $\alpha-, \beta$-, and KIP were provided by Zhejiang NHU Co., Ltd. 5,10,15,20-Tetraphenyl-21 H, 23 H-porphine Chromium (III) Chloride and 5,10,15,20-Tetraphenyl-21 H,3 H-porphine Copper (II) were synthesized according to published procedures. [22]Iron (III) meso-Tetraphenylporphine chloride from Strem Chemicals (lot\# 21194200), 5,10,15,20-Tetraphenyl-21 H,23 H-porphine Cobalt (II) (lot\# MKBK2841V) and 5,10,15,20-Tetraphenyl-21 H,23 H-porphine Manganese (III) Chloride from Sigma Aldrich lot\# 01909MEV).

\subsection{Experimental methods}

Experiments were conducted in two separate $50 \mathrm{ml}$ three neck flasks with equal parts pyridine to $\beta$-IP by volume in $20 \mathrm{ml}$ of solution. The flasks were heated using a heating mantle to temperatures ranging from 60 to $75^{\circ} \mathrm{C}$. Porphyrin catalysts were added from a concentrated pyridine solution such that 1:1 ratio pyridine to $\beta$-IP was maintained. Both reaction containers were attached to $1.5 \mathrm{~cm}$ diameter silicone oxygen supply tubes, which were individually regulated through the use of flow meters. Oxygen flow was calibrated to no greater than a 5\% difference between each reaction container. A \#10 Gauge needle was attached to the oxygen supply tube and 
pushed through a rubber stopper to supply oxygen directly into reaction solution. The orientation of needle was positioned as to be identical in both reaction containers. This detail was later understood as crucial for determining the reaction rates. Copper wiring was tied around every connection to ensure that the reaction vessels were airtight. Condensers were attached to each reaction container and an additional glass plug was inserted on the last neck to provide easy access to withdraw solution and a polytetrafluoroethylene (PTFE) coated stir bar was added. Safety control heating blocks warmed water baths to desired reaction temperature. Stock catalyst solutions were calibrated daily using UV-Vis techniques. $0.1 \mathrm{ml}$ aliquots were withdrawn every hour for gas chromatographic (GC) analysis using Shimadzu Gas Chromatograph-GC-2014.

Absorption spectra were obtained on a HP8453 photodiode array spectrophotometer. Samples were dissolved in appropriate mixtures of pyridine and $\beta$-IP as solvents to mimic the experimental conditions. Absorption spectra were collected using $1 \mathrm{~cm}$ path length quartz cuvettes from 200 - $700 \mathrm{~nm}$. Raman spectra were obtained in spinning cell using a backscattering geometry. Excitation was achieved using a tunable Raman spectrometer constructed using a Ti:sapphire laser (Coherent Mira900) pumped by a Verdi diodepumped Nd:YLF laser. The detection system consisted of a triple-monochromator (SPEX 1877) and a $\mathrm{LN}_{2}$ cooled CCD detector. Spectra were collected for 20 minutes for laser wavelengths tuned to $410-415 \mathrm{~nm}$.

\subsection{Computational methods}

Density functional theory calculations were carried out using the code $\mathrm{DMol}^{3}$. [23, 24] The PBE functional [25] was selected and calculations were carried out using the THERMAL option.[26] The THERMAL keyword permits non-integer electron populations, which have been shown to aid in convergence, particularly in large molecules [27]The THERMAL parameter, which is an electronic temperature was set to 0.005 (atomic units). The final energies are reported with application of a correction to $\mathrm{T}=0 \mathrm{~K}$. The molecules studied here contained up to 112 atoms, including one transition metal. The transition metals, Cr, Mn, Fe and Co were studied most intensively. The oxidation state was assumed to be +3 for all metals except $\mathrm{Cu}$, where it was assumed to be $\mathrm{Cu}^{2+}$. In addition, studies on the reduced forms were conducted and the energetics of electron transfer were studied in order to consider a potential role for oxy adducts of the metal complexes. The spin states for weak field ligands are high spin, which applies to pyridine as well as chloride and 
acetate. [28, 29] The spin crossover occurs for stronger field ligands such as isothiocyanate. [30, 31] The molecules were geometry optimized until a convergence of $<10^{-6}$ Hartrees per iterative step was reached. [32] To account for the effects of charged ligands or MTPP complexes, the calculations were also carried out using a dielectric continuum solvent model (COSMO). [33, 34] Calculations of electronic spectra were conducted using the TDDFT method within DMol ${ }^{3}$. Computations were conducted at the North Carolina State University High Performance Cluster, the Advanced ARC cluster on NCSU campus and Center of Applied Computational Studies at East Carolina University campus. [35]

\section{Results}

Aerobic oxidation of $\beta$-IP to KIP was compared using various MTPP catalysts $(\mathrm{M}=\mathrm{Cr}, \mathrm{Mn}, \mathrm{Fe}, \mathrm{Co}, \mathrm{Cu})$ over the course of 7 hours (Table 1). The yield of KIP as well as the side-product ( $\alpha$-IP) was measured at various time points over the course of the reaction using GC as shown in Figures 2A and 2B. All reactions were performed in a solvent composed of 50\% $\beta$-IP: 50\% Pyr by volume. A study of solvent effects of varying ratios of $\beta$-IP and Pyr showed that a 50\% vol. mixture of the two solvents gives the maximum rate, although the maximum is fairly broad and nearly the same rate is achieved with a $66.6 \% \beta$-IP: $33.3 \%$ Pyr solvent system (Figure S4). The kinetic trends were similar for most of the MTPPs, showing a sublinear time course that is indicative of consumption of the reactant. However, MnTPP was an exception, showing a slightly superlinear increase in rate over time (Figure 3B). This suggests that a precatalyst transforms to a more reactive species over the course of the reaction. Resonance Raman (rRaman) spectroscopy shows that MnTPPAc changes in the presence of $\beta$-IP suggesting that ligation of $\beta$-IP with the Mn ion may be crucial for the catalytic mechanism. DFT calculations show that $\beta$-IP has uniquely strong bond with Mn compared to the other metals. This can be seen in Table 2 where ligation strength of the various possible MnTPP complexes is compared. In addition to altering the metal identity, activation barriers for catalysis were obtained by varying reaction temperature (Table 3). We found that in order to obtain reproducible results we had to carefully control the conditions that affected the $\mathrm{O}_{2}$ concentration in solution. 


\subsection{Comparison of the activity of MTPP catalysts $(\mathrm{M}=\mathrm{Cr}, \mathrm{Mn}, \mathrm{Fe}, \mathrm{Co}, \mathrm{Cu})$}

KIP is the desired product of $\beta$-IP oxidation. However, the stable isomer $\alpha$-IP is a significant side product in all reactions, in which $\beta$-IP is used as a starting material. While $\alpha$-IP forms spontaneously most catalysts also accelerate the conversion of $\beta$-IP to the undesired side product $\alpha$-IP. Figure 3A shows that the yield of the $\alpha$-IP isomerization side product appears to be greatest in CrTPP and by far the smallest for MnTPP for data obtained at $60{ }^{\circ} \mathrm{C}$. While all MTPP catalysts produced greater concentrations of KIP than the nocatalyst control, all of them except MnTPP also had higher $\alpha$-IP yields than the control (Figure 3A). Concentrations of KIP appear to increase linearly without added catalyst, but tended to level off over time in the presence of catalyst. MnTPP defied that trend with what appears to be superlinear increase in concentration of KIP (Figure 3B). Figure 3D shows that decrease in $\beta$-IP concentration caused by its conversion corresponds to the increase of KIP production. A plot of the product ratio $[\mathrm{KIP}] /[\alpha-\mathrm{IP}]$ indicates that most MTPP catalysts have a similar trend, with maximum selectivity achieved at the 2 hour mark in the reaction (Figure 3C). MnTPP has the greatest selectivity for KIP over $\alpha$-IP, however FeTPP was also distinctly better than the other metals tested. The maximum selectivity for KIP was found in hour 6 when MnTPP was employed under these reaction conditions (Table 4).

\subsection{Effect of temperature on the reaction kinetics}

Rates were plotted over the temperature range from 60 to $75{ }^{\circ} \mathrm{C}$ and the activation energy was calculated using the Arrhenius equation: $k=A e^{-E_{a /(R T)}}$, where $\mathrm{E}_{\mathrm{a}}$ is the activation energy (see Supporting Information). Based on the slopes of the fitted lines, which are equal to $-\mathrm{E}_{\mathrm{a}} / \mathrm{R}$, the activation enthalpies were determined to be $11.3 \mathrm{kcal} / \mathrm{mol}, 23.3 \mathrm{kcal} / \mathrm{mol}$, and $-2.5 \mathrm{kcal} / \mathrm{mol}$ for CoTPP, MnTPP, and FeTPP, respectively (Table 3). 


\subsection{Spectroscopic characteristics of the ligated forms of MTPP}

The solvent plays an active role in this reaction since pyridine (Pyr) can act as a base. The other component of the solvent is the substrate, $\beta$-IP. Finally, both Pyr and $\beta$-IP can act as ligands to MTPP. Our proposed mechanism requires that $\beta$-IP displaces either a Pyr or an anionic (chloride or acetate) ligand at the metal center. To help determine if either species selectively binds to the metal centers, electronic absorption and rRaman spectra of the two most active catalysts, FeTPP and MnTPP, were obtained in Pyr with various percentages of $\beta$-IP added to form solvent mixtures up to 50:50 $\beta$-IP:Pyr. The rRaman spectra of CrTPP and CoTPP complexes are given in the Supporting Information (Figures S1 and S2). Where comparisons can be made, the rRaman spectra had similar features to studies of MTPP in the recent literature.[36] Unlike FeTPP and MnTPP the CrTPP and CoTPP complexes show no spectral change when $\beta$-IP is added, suggesting that $\beta$-IP does not ligate to $\mathrm{Cr}$ or Co metal centers. The lack of interaction of the substrate with the catalyst may be one reason that these two MTPPs are not good catalysts. The complexes were also studied by EAS under anaerobic conditions and no change was observed relative to samples prepared in air, from which it was evident that $\mathrm{O}_{2}$ is not bound to the metal under the experimental conditions. This is not surprising since neither Fe(III) nor $\mathrm{Mn}(\mathrm{III})$ are known to bind $\mathrm{O}_{2}$. In studies of both gas[37] and solution phase[37] reactions a $\mu$-oxo bridged dimer can be formed, but the $\mathrm{O}_{2}$ adduct is observed only in the Fe(II) and Mn(II) oxidation states. [38, 39] UV-visible spectra of MnTPP and FeTPP are shown in Figure 4 for various volume fractions of $\beta$-IP in pyridine ranging from 0.0 to 0.5 . The change in the MnTPP spectrum is indicative of a change in the ligation of Mn from MnTPP(Pyr)Ac to a Pyr and $\beta$-IP ligated adduct, MnTPP(Pyr) $\beta$-IP $\mathrm{I}^{+}$in the $50 \% \beta$-IP solvent (Figure S8). We cannot rule out the possibility that $\mathrm{MnTPP}(\mathrm{Pyr})_{2}{ }^{+}$is present in neat Pyr and therefore that ligand replacement involves a conversion from $\mathrm{MnTPP}(\mathrm{Pyr}){ }_{2}{ }^{+}$to $\operatorname{MnTPP}(\mathrm{Pyr}) \beta-\mathrm{IP}^{+}$. For FeTPP the spectral changes are entirely different than that of MnTPP, suggesting that an alternative ligation pattern is present. However, the data still suggest that sufficiently high $\beta$-IP concentration will lead to $\beta$-IP binding to Fe. Based on modeling of the UV-Vis spectra using TDDFT calculations, there are two possible scenarios that could explain the binding of $\beta$-IP to the Fe atom. The absorption spectrum for the starting material FeTPPCl dissolved in pyridine has $\lambda_{\max }=424 \mathrm{~nm}($ Figure $4 \mathrm{~B})$. Based on the TDDFT calculation it is difficult to distinguish between FeTPP(Pyr $)_{2}$ and FeTPP(Pyr $) C l, \lambda \max =429 \mathrm{~nm}$ and $430 \mathrm{~nm}$, respectively, 
either of which may be present in neat pyridine solvent (see Figures S8D and 8C). For the situation with 1:1 $\beta$-IP:Pyr as the solvent, TDDFT calculated spectra are significantly different. The calculated spectra shown in Figure S8C are by far most consistent with the presence of $\operatorname{FeTPP}(\beta-\mathrm{IP}) \mathrm{Cl}$ in the mixed solvent. For this reason we find that the TDDFT calculations are also consistent with retention of the chloride ligand in neat pyridine and replacement of the pyridine trans to $\mathrm{Cl}^{-}$by $\beta$-IP, i.e. $\mathrm{FeTPP}(\mathrm{Pyr}) \mathrm{Cl} \rightarrow \mathrm{FeTPP}(\beta-\mathrm{IP}) \mathrm{Cl}$, which in turn suggests that FeTPP(Pyr)Cl is present in neat pyridine solution. This conclusion is in agreement with NMR studies of related adducts of tetraphenylchlorin with a series of basic ligands. [40] Pyridine is a relatively weak base and is therefore unlikely to displace the $\mathrm{Cl}^{-}$ion here.

Evidence for a change in ligation in MnTPP and FeTPP is also found in the rRaman spectra shown in Figure 5. The four panels of Figure 5 show a comparison of low frequency rRaman (excited at $417 \mathrm{~nm}$ ) for four of the catalysts (CrTPP, CoTPP, FeTPP and MnTPP) in two solvents (neat pyridine or Pyr and $\beta$-IP in a 50\%/50\% by volume mixture). Neither CrTPP nor CoTPP, which are less active catalysts, showed any change in the Raman spectrum when the composition of $\beta$-IP is increased to 50\% by volume. However, both MnTPP and FeTPP show differences. The modest change in the FeTPP spectrum would appear to be most consistent with a replacement of pyridine by $\beta$-IP. The much large change observed in the MnTPP spectrum is consistent with the proposed replacement of acetate by $\beta$-IP, i.e. MnTPP(Pyr)Ac $\rightarrow \operatorname{MnTPP}(\mathrm{Pyr}) \beta-\mathrm{IP}^{+}$.

\subsection{Density Functional Theory Calculations}

Based on the observations from UV-visible and rRaman spectroscopy we continued to explore the possibility that the substrate, $\beta$-IP, ligates to the metal center of the TPP catalysts in the $3+$ state using DFT (Cr(III)TPP, Mn(III)TPP, Fe(III)TPP and Co(III)TPP). This could, in turn, lead to substrate activation for hydrogen abstraction. The $3+$ oxidation state is expected in an aerobic environment, but this required investigation to determine whether reduction of any of the metals by $\beta$-IP is possible under the reaction conditions. Since such a mechanism had been proposed previously, [41] we further explored the possibility of metal center reduction, however our calculations show that neither $\beta$-IP nor pyridine can directly reduce any of the M(III)TPP used in this study in agreement with the known 
reduction potentials. [42] Moreover, there was no evidence of $\mathrm{O}_{2}$ binding in any of the experiments. Thus, no further research was done along these lines (see Supporting Information Tables S12-S15). Since the catalyst does not bind nor activate $\mathrm{O}_{2}$, the role played by the catalyst is most likely substrate activation. We suggest that the major pathway for oxidation is initiated by abstraction of a hydrogen atom or ion either by a radical or base catalyzed pathway, respectively (Figure 2).

To test the hypothesis that bonding of $\beta$-IP to MnTPP or FeTPP may reduce the barrier for hydrogen abstraction, a complete set of DFT calculations for all combinations of the ligands $\beta$-IP, $\mathrm{Pyr}$ and $\mathrm{Ac}^{-} / \mathrm{Cl}^{-}$(for $\mathrm{Mn} / \mathrm{Fe}$, respectively) was conducted to determine the binding affinity of the metal for each ligand separately or in combination (Tables S5 and S7 in the Supporting Information). The binding energy of $\mathrm{Cl}^{-}$and $\mathrm{Ac}^{-}$appear to be accurately modeled when the COSMO dielectric continuum model is used. Since $\alpha$-IP is also able to bind to the metal, in order for the catalyst to increase the selectivity of the reaction it must selectively activate $\beta$-IP over $\alpha$-IP. To test this idea, calculations were conducted for $\beta$-IP and $\alpha$-IP and radical intermediates, both free in solution and bound to M(III)TPPs. The binding affinity of $\alpha$-IP and $\beta$-IP was determined using models, in which the oxygen atom of the keto group on $\alpha$-IP or $\beta$-IP was pointed towards the metal of a $\operatorname{MTPP}(\mathrm{Pyr})^{+}$or $\operatorname{MTPP}(\mathrm{Ac} / \mathrm{Cl})$, with a trans pyridine and acetate or chloride ligands, respectively, are present as shown in Figure S5. The use of the COSMO dielectric continuum model was essential when anionic ligands were considered.

The structure of the FeTPPCl adduct obtained here is in excellent agreement with previous DFT studies. [29] The Fe-Cl bond length is $2.22 \AA$, in quantitative agreement with experiment. [43] The calculated $\mathrm{Mn}-\mathrm{Cl}$ bond length of the 5-coordinate MnTPPCl is $2.26 \AA$, which is slightly less than the crystallographically determined $2.29 \AA$ A.[44] While the structures of the anionic $\mathrm{Cl}^{-}$ligand adducts of MTPP are in excellent agreement with experiment, accurate binding energies are obtained only when the COSMO dielectric continuum model is included. [28] First, we considered the binding of the solvent pyridine to MTPPCl. There are two possible overall reactions, addition of pyridine trans for $\mathrm{Cl}^{-}$(I) and addition of a second equivalent of pyridine with concomitant displacement of $\mathrm{Cl}^{-}$to form a dipyridine adduct (II). 
$\operatorname{MTPP}(\mathrm{Pyr}) \mathrm{Cl}+\mathrm{Pyr} \rightarrow \mathrm{MTPP}(\mathrm{Pyr})_{2}{ }^{+}+\mathrm{Cl}^{-}$

Although the overall reaction to form the bis-pyridine adduct is energetically favorable for all metals, the MnTPPCl complex is unusually stable. The energy difference for addition of Pyr given by reaction (I) is $\Delta \mathrm{E}=-0.4 \mathrm{kcal} / \mathrm{mol}$ for MnTPPCl, but it is significantly larger for the other MTPPCl complexes (Table 5). The reaction for Fe is interesting because reaction (I) is favored by a spin-crossover from high spin to low spin. The relative spin state energies of the complexes are given in Table S17 in the Supporting Information. The energies are accurate only if the COSMO solvation model is employed and the spin state ordering is reasonable only when the extended basis set is used in $\mathrm{DMol}^{3}$. MTPPCl species have favorable binding energies for pyridine coordination via reaction (I). This is known experimentally for CrTPPCl.[45] Although the energy of reaction (II) is unfavorable for Fe, the energy of reaction (I) is sufficiently large that the formation of the bis-pyridine adduct is exothermic. While Fe and $\mathrm{Mn}$ have spin crossover reactions (I), reaction (II) is favored for the low spin state of each metal, $\mathrm{S}=1 / 2$ and 1, respectively. On the other hand, the reactions are favorable high spin Cr ( $\mathrm{S}$ $=3 / 2)$ and $\mathrm{Co}(\mathrm{S}=2)$. The stability of the $\mathrm{Co}$ and $\mathrm{Cr}$ bispyridine adducts may be one reason that further changes in ligation are not observed when $\beta$-IP is added to the solution. The relative stability of the initial MnTPPCl adduct appears to explain why this species is does not bind $\beta$-IP experimentally. Instead, we used the acetate (Ac) adduct, MnTPPAc, which has energies of $\Delta \mathrm{E}=-12.2$ and +0.3 $\mathrm{kcal} / \mathrm{mol}$ for reactions (I) and (II), respectively. A key aspect of our hypothesis is that $\beta$-IP can interact with the metal to permit the formation of catalytic intermediates. In the case of CoTPP, the equilibrium structures do not have stable Co-O bonds, which appears to rule out a role for $\beta$-IP ligation to CoTPPs as observed in UV-vis and resonance Raman experiments. This result is consistent with the relative stability of the CoTPP(Pyr $)_{2}{ }^{+}$complex given in Table 5.

Based on the study of reactions (I) and (II) and the experimental observations we decided to proceed with more detailed studies of FeTPP and MnTPP in order to further to understand their interactions with $\beta$-IP. The chemistry of FeTPP and MnTPP differ because the differing affinity for $\mathrm{Cl}^{-}$, such that FeTPPCl is considered an active species while MnTPPCl is not. Neither Pyr nor $\beta$-IP is observed 
to be stable trans to $\mathrm{Cl}^{-}$in $\mathrm{Mn}$. Because of the poor catalytic activity of $\mathrm{MnTPPCl}$, the $\mathrm{Ac}^{-}$salt was used during synthesis of MnTPP to make MnTPPAc. Based on the UV-vis spectra and the large change in the resonance Raman spectrum we propose that the change in ligation that occurs in the 50:50 $\beta$-IP:Pyr solvent involves the ligation of $\beta$-IP to the metal center. The reaction of $\beta$-IP with the MTPP(Pyr)X complex leads to two possible products, MTPP(Pyr) $\beta$-IP ${ }^{+}$and M( $\beta$-IP)X as shown in reactions (III) and (IV)

$\mathrm{MTPP}(\mathrm{Pyr}) \mathrm{X}+\beta-\mathrm{IP} \rightarrow \mathrm{MTPP}(\mathrm{Pyr}) \beta-\mathrm{IP}^{+}+\mathrm{X}^{-}$

$\operatorname{MTPP}(\mathrm{Pyr}) \mathrm{X}+\beta-\mathrm{IP} \rightarrow \mathrm{MTPP}(\beta-\mathrm{IP}) \mathrm{X}+\mathrm{Pyr}$

where $\mathrm{M}=\mathrm{Mn}$ or $\mathrm{Fe}$ and $\mathrm{X}^{-}=\mathrm{Cl}^{-}$or $\mathrm{Ac}^{-}$. The end result is the same with $\beta$-IP bound trans to pyridine in a six-coordinate adduct. The resonance Raman spectra indicate that the spectral changes indicate ligation of $\beta$-IP occurs to some extent for both $\mathrm{M}=\mathrm{Fe}$ and $\mathrm{Mn}$. For Fe the spectral data are more consistent with an active species of FeTPP( $\beta$-IP)Cl, which could be formed in the 50\% by volume $\beta$-IP solvent by replacement of the pyridine ligand trans to $\mathrm{Cl}^{-}$. The equilibrium that links Pyr and $\beta$-IP is given by Eqn. (V)

$\operatorname{MTPP}(\mathrm{Pyr})_{2}{ }^{+}+\beta-\mathrm{IP} \rightarrow \mathrm{MTPP}(\mathrm{Pyr}) \beta-\mathrm{IP}^{+}+\mathrm{Pyr}$

The calculated energies of these reactions are given in Table 6.

The FeTPP $\left(\beta\right.$-IP)Cl complex is clearly less thermodynamically favorable than FeTPP(Pyr) $\beta$-IP ${ }^{+}$(Table 6). However, the calculated equilibrium constant for formation of $\mathrm{FeTPP}(\mathrm{Pyr}) \beta-\mathrm{IP}^{+}$by reaction $(\mathrm{V})$ is not sufficiently large to explain the resonance Raman or UV-vis data, which show a significant degree of exchange when the FeTPP adduct is dissolved in 50\% by volume $\beta$-IP. These are calculations with large basis sets and the enthalpies of solvation of pyridine and $\beta$-IP should be very small since they have no electrostatic component. The anionic component of the binding interactions by $\mathrm{Cl}^{-}$and $\mathrm{Ac}^{-}$can be accurately calculated using COSMO. $[28,46]$ From a computational point of view it appears that there is little more that can be done to achieve better agreement with regard to these reactions. 
For most of the calculations the double-numerical basis set was used. The triple numerical basis set is essential when comparisons between spin states are required. [47] However, within one spin manifold the double-zeta basis set has been shown to give good results. [48-50] Based on this level of calculation the calculated structures agree with the experimental trends. Both $\beta$-IP and Pyr have significant stabilization in the $\mathrm{FeTPP}(\beta-\mathrm{IP}) \mathrm{Pyr}^{+}$and $\mathrm{MnTPP}(\beta-\mathrm{IP}) \mathrm{Pyr}^{+}$adduct relative to either of the adducts in which $\mathrm{Pyr}$ or $\beta$-IP is trans for Cl-. In the geometry optimized structures of these complexes $\beta$-IP remained bound trans to Pyr for $\mathrm{CrTPP}(\mathrm{Pyr}) \beta-\mathrm{IP}{ }^{+}, \mathrm{FeTPP}(\mathrm{Pyr}) \beta$-IP ${ }^{+}$and $\operatorname{MnTPP}(\mathrm{Pyr}) \beta-\mathrm{IP}^{+}$, but not for CoTPP(Pyr $)^{+}$or $\mathrm{CuTPP}(\mathrm{Pyr})^{+}$. The M-O bond lengths of the geometry optimized structures were 2.09, 2.22 and $2.05 \AA$ A , respectively, in $\operatorname{CrTPP}(\mathrm{Pyr}) \beta-\mathrm{IP}^{+}, \mathrm{FeTPP}(\mathrm{Pyr}) \beta-\mathrm{IP}^{+}$and MnTPP(Pyr) $\beta-\mathrm{IP}^{+}$(see Table 7).

A mechanistic explanation for the role of the MTPP catalyst was sought by study of the MTPP $(\beta \text {-IP })^{+}$adducts. In principle, the binding of $\beta$-IP to a metal may lower the barrier for hydrogen abstraction and thereby favor the radical pathway. Moreover, binding to the metal may favor the trans resonance structure and the binding of $\mathrm{O}_{2}$ in the para-position, improving the selectivity of the reaction. However, these calculations must also account for the possibility that the byproduct $\alpha$-IP could also be activated by a similar mechanism. Thus, parallel DFT calculations were conducted for $\beta$-IP and $\alpha$-IP bonded to MnTPP adducts. The calculations were also done for the Pyr and $\mathrm{Ac}^{-}$trans adducts. The structures of these are shown in Figure 6. While the thermodynamic calculation of $\beta$-IP binding suggests can be displaced by Pyr in both FeTPP(Pyr) $\beta$-IP and MnTPP(Pyr) $\beta$-IP, the calculated potential energy profile for removal of $\beta$-IP from the metal suggested a strong bond in both metals with a well depth of ca. $15 \mathrm{kcal} / \mathrm{mol}$ (see Figure S6). Figure 6 shows that the $\beta$-IP adduct is strongly ligated for both the Pyr and $\mathrm{Ac}^{-}$forms of MnTPP. Based on these considerations FeTPP(Pyr) $\beta$-IP was deemed the better candidate for a catalytic intermediate.

To test the hypothesis that $\beta$-IP is bound to the Fe and accounts for the spectroscopic observations, the hydrogen abstraction pathway was further analyzed in terms of the geometry of $\beta$-IP and $\alpha$-IP as shown in Figure 6 . The relatively strong interaction of both $\beta$-IP and $\alpha$-IP with MTPP means that the observed difference in reactivity is due to more subtle effects than simple competitive binding 
on the catalyst. Instead, as shown in Figure 6 the specific hydrogen abstraction sites for each molecule needs to be compared. These are labeled as $\mathrm{sp}^{2}$ and $\mathrm{sp}^{3}$ sites. First, we note that the $\mathrm{sp}^{3}$ sites are favored for hydrogen abstraction. In the case of free $\beta$-IP, the abstraction energy is $\sim 7 \mathrm{kcal} / \mathrm{mol}$ less than for $\alpha$-IP due to the lack of conjugation from the $\pi$-system. Note that the same intermediate is obtained by hydrogen abstraction from the $\mathrm{sp}^{3}$ site of both $\beta$-IP and $\alpha$-IP. We have labeled this radical intermediate INT, to distinguish it from the higher energy $\mathrm{sp}^{2}$ hydrogen abstraction processes. The change in the hydrogen abstraction energy obtained by binding of either $\beta$ IP or $\alpha$-IP to the MTPP is given Table 8 . It is evident that the $\mathrm{sp}^{3}$ site is further favored after metal binding, while the abstraction from the $\mathrm{sp}^{2}$ site remains disfavored. The values in Table 8 are difference energies of the reaction for $\beta$-IP or $\alpha$-IP on the MTPP relative free $\beta$-IP or $\alpha$-IP (see Supporting Information for details of this calculation). Table 8 shows that energy required for hydrogen abstraction from the $\mathrm{sp}^{3}$ site on $\beta$-IP is reduced by $15.6 \mathrm{kcal} / \mathrm{mol}$ when the substrate is ligated to FeTPP. This is greater than the energy reduction for the $\mathrm{sp}^{3}$ site of $\alpha$-IP, which is $12.3 \mathrm{kcal} / \mathrm{mol}$. For MnTPP the reduction is $\sim 12 \mathrm{kcal} / \mathrm{mol}$ for both $\beta$-IP and $\alpha$-IP $\mathrm{sp}^{3}$ sites. Since these are relative energies, it should be noted that the energy hydrogen abstraction is still $\sim 7 \mathrm{kcal} / \mathrm{mol}$ lower for $\beta$-IP than for $\alpha$-IP. In conclusion, we find strong evidence for the hypothesis that the binding of the $\beta$-IP substrate to the metal in FeTPP and MnTPP provides a significant reduction in energy of hydrogen abstraction. The net energy required for hydrogen abstraction is only about $\sim 1 \mathrm{kcal} / \mathrm{mol}$ for $\beta$-IP bound to MnTPP(Pyr $)^{+}$, while it is $\sim 8 \mathrm{kcal} / \mathrm{mol}$ for $\alpha$-IP.

The rate constants under the conditions reported at $70{ }^{\circ} \mathrm{C}$ are given in Table 9 for the blank, with no added catalyst and the three most active MTPP catalysts. These rate constants provide a quantitative metric for the relative effect on both the rate of KIP formation and the selectivity. These are initial rate constants, which were taken over the linear portion of the data in all cases. The range used was from zero to four hours. If one compares only KIP formation the best catalyst appears to be FeTPP, which has a relative rate constant 2.4 times greater than the blank. By contrast MnTPP has a rate constant 1.9 times greater. However, the important difference in the catalysts is observed when $\alpha$-IP formation is considered. FeTPP accelerates $\alpha$-IP formation by a factor of 1.3, while MnTPP decreases 
the formation by a factor 5 . Thus, the net relative change in formation, i.e. the change in the ratio $[\mathrm{KIP}] /[\alpha-\mathrm{IP}]$ is 1.8 for FeTPP and 8.5 for MnTPP. Thus, MnTPP is by far the best catalyst from the point of view of selectivity of formation of KIP product.

\section{Discussion}

In this study, MnTPP was found to be the best catalyst from the point of view of selectivity, while MnTPP and FeTPP are rivals for the best catalyst in terms rate of conversion of $\beta$-IP to KIP. Comparison of MTPPs for other reactions such as the oxidative cleavage of cinnamaldehyde have also found that MnTPP is the most active catalyst.[41] The superlinear production of KIP catalyzed by MnTPP suggests that one possible explanation for the unique behavior of MnTPP arises from its conversion into a more active species during the course of the reaction. The effect may also be due to the production of $\mathrm{H}_{2} \mathrm{O}$ during the course of the reaction, which will change the solvent dielectric constant and increase the solvation of the ionic species such as $\mathrm{Cl}^{-}$and $\mathrm{Ac}^{-}$. This change could alter the binding constant for $\mathrm{Ac}^{-}$and affect the ligation of $\mathrm{Mn}$. Given the relatively low solvent $\mathrm{pH}$ in these solutions, once $\mathrm{H}_{2} \mathrm{O}$ is formed in the course of the reaction, we deemed it unlikely that a $\mu$-oxo dimer is formed. Formation of a $\mu$-oxo dimer is known due to interaction of $\mathrm{OH}^{-}$ under high $\mathrm{pH}$ conditions.[51] Thus, none of the above mentioned factors were considered in the computational models. Instead, the models focused on the most reasonable hypothesis based on the spectroscopic evidence, which is that $\beta$-IP can ligate to Mn, which could lead to activation of the molecule for $\mathrm{H}$ abstraction through a radical mechanism.

Table 4 gives an analysis of the maximum selectivity [KIP]/[ $\alpha$-IP]for each of the MTPPs with respect to $\beta$-IP consumption and the production of the desired product KIP. The complementary analysis in terms of the undesired side product $\alpha$-IP is provided in Table $\mathrm{S} 19$. As indicated above formation of $\mathrm{H}_{2} \mathrm{O}$ may play a role in the process. This is not surprising given the change in solvent polarity that occurs as the reaction proceeds. $\mathrm{As}_{2} \mathrm{O}$ is formed the solvent changes from an aprotic non-polar solvent to a protic polar solvent. One hypothesis is that the decline in selectivity for most of the MTPPs as the reaction proceeds might be due to the production of $\mathrm{H}_{2} \mathrm{O}$, which is an inherent product of the oxidation reaction. [6] Protic solutions have been shown to reduce the specificity for KIP formation. [5, 21] 
In the proposed mechanism shown in Figures 1 and 2, the radical intermediate may readily be quenched by radical proton capture, which forms unwanted products such as $\alpha$-IP. [21] Since $\alpha$-IP is the more thermodynamically stable molecule, strategies for synthesizing KIP based on production of $\beta$-IP must always contend with the competing isomerization to form $\alpha$-IP. Water has been shown to halt reactivity in a separate iodine-initiated $\alpha$-IP radical-based mechanism. [10] Although the production of $\alpha$-IP appears to increase exponentially (Figure 3) over the course of the experiment for all metals, $\alpha$-IP production does not follow the kinetics of KIP formation. The catalytic role of MTPPs appears to separately affect the formation of the desired product KIP and undesired side product $\alpha$-IP, For example, while MnTPP shows a slower growth of $\alpha$-IP production with an increase in rate of KIP formation, CoTPP had the opposite effect of $\alpha$-IP and a negligible effect on KIP formation. We propose that these differences are a function of how well the substrate, $\beta$-IP, interacts with the metal complex.

The Arrhenius analysis of the rate constant measured as a function of temperature provides an activation energy of $23.3 \mathrm{kcal} / \mathrm{mol}$ for the MnTPP adduct (Table 3). In a similar experiment using a salenMn(III)Cl as the oxidation catalyst, the activation energy was estimated at $16.1 \mathrm{kcal} / \mathrm{mol}$.[7] Co(II) Saloph complexes embedded in zeolite at $30^{\circ} \mathrm{C}$ and using compressed air had a calculated activation energy of $12.3 \mathrm{kcal} / \mathrm{mol}$. [14] In the present case, the relatively large activation energy likely depends on the binding of $\beta$-IP trans to acetate in the MnTPP combined with the hydrogen abstraction step. Once the reaction has taken place on the metal and KIP product has been formed, $\beta$-IP must displace KIP in order to continue the catalytic process. The energy requirements of this step for either the FeTPP or MnTPP complexes may be quite different.

The experimental configuration does not permit detailed studies of the rate law. Running the reaction at low $\mathrm{O}_{2}$ concentrations results in both long reaction time and uncertainty in the pressure that renders accurate rate law determination difficult. Although we lack experimental evidence at this time, the simplest analysis of the data obtained yields a rate law with a linear dependence on $\left[\mathrm{O}_{2}\right](\mathrm{see}$ Supporting Information). This differs from the published rate law with a dependence $\left[\mathrm{O}_{2}\right]^{1 / 2}$, which was determined empirically. [1] The simplest case of a rate law does not account side reactions or the role of $\mathrm{H}_{2} \mathrm{O}$, which are known to play a role in the formation of $\alpha$-IP, 
and can lead to a loss of selectivity. Such reactions may well reduce the dependence of the product on $\left[\mathrm{O}_{2}\right]$ from linear to sublinear, which account for the observed differences in the empirical rate law compared to our simplest theoretical model. The point of these considerations is that these rate laws are consistent with the proposal that the catalytic mechanism arises from the binding of $\beta$-IP to the metal center. In previous studies of MTPP catalyzed oxidation it has been suggested that cinnamaldehyde is able to reduce Co, Fe and Mn in their respective TPPs from the $3+$ to the 2+ state as a key step in its catalytic oxidation to benzaldehyde. [41] Of course, if the metal in TPP is reduced to the $2+$ it would permit $\mathrm{O}_{2}$ binding and activation. Nonetheless, the experiments conducted in this study do not provide any evidence for $\mathrm{O}_{2}$ binding in either the UV-vis or rRaman spectra of $\beta$-IP:Pyr mixtures, which provides experimental evidence to discount a MTPP reduction mechanism. Moreover, DFT calculations show that none of the components of the reaction are capable of reducing the MTPPs to the 2+-oxidation state needed for binding $\mathrm{O}_{2}$ on their own. Because we lack a catalytic mechanism that explains $\mathrm{O}_{2}$ activation and we have evidence for ligand exchange, we advance the hypothesis that the substrate $\beta$-IP itself becomes a ligand and is thereby activated for hydrogen abstraction.

The detailed high-level DFT calculations show that this hypothesis is reasonable, although questions remain. In mixed Pyr/ $\beta$-IP solvent, both molecules have sufficiently high activity that they can bind trans to $\mathrm{Cl}^{-}$(in Fe, Co and CrTPP) and trans to Ac in MnTPP. However, the resonance Raman data suggest that ligand exchange takes place when the complex is transferred from neat Pyr to mixed Pyr/ $\beta$-IP, while the DFT calculations suggest that the energy for exchange by $\beta$-IP is not highly favorable (at least for MnTPP).

\section{Conclusion}

Based on the UV-Vis, rRaman data and DFT calculations we have proposed a model of activation by binding of $\beta$-IP to the metal ion in the MTPP. This model is consistent with higher selectivity of Mn relative to the other MTPPs studied. The concept behind the model is that the pattern of activation of the $\mathrm{C}-\mathrm{H}$ bonds for hydrogen abstraction is altered due to interaction of $\beta$-IP with the metal. The experiments show that MnTPP is the most efficient and selective catalyst for $\beta$-IP oxidation within the group of MTPP catalysts selected for study. MnTPP appears qualitatively different from the other MTPP catalysts in that it is the only catalyst that does not show 
superlinear growth of $\alpha$-IP. The second best catalyst identified in our study, FeTPPCl appears to be sufficiently labile that $\beta$-IP can bind, most likely by displacing the $\mathrm{Cl}^{-}$. On the other hand, this does not occur for MnTPPCl and one must use acetate instead (MnTPPAc) in order to obtain the same effect.

Given the recent interest in heterogeneous catalysis for the oxidation of $\beta$-IP $[4,12,14,52]$ and the large number of studies demonstrating the efficacy of porphyrin oxidation catalysts [53-56] it is reasonable to suggest that MTPPs may be immobilized to find more efficient catalysts. Heterogeneous compounds are easy to separate and reuse for cleaner and more efficient chemical reactions. With a better understanding of the chemical reaction of MTPP compounds in liquid phase, research would benefit from better understanding on the impact of structural changes and solution effects upon the activation of oxygen product formation. Our understanding of the role of the geometry of the bound $\beta$-IP will aid in such catalyst design.

Acknowledgments. We gratefully acknowledge support from the NSF through grant 0958311, which supported the calculations conducted on the Advanced ARC cluster, the High Performance Cluster at North Carolina State University as well as the Center of Applied Computational Studies at East Carolina University for providing computational resources to support some of the calculations reported in this paper. TH and WWW acknowledge generous NCSU startup funding. SF acknowledges support from the Zhejiang University Guangbiao Scholars Fund.

\section{References}

[1] W. Bonrath, T. Netscher, Appl. Catal. a-Gen., 280 (2005) 55-73.

[2] M. Soukup, E. Widmer, T. Lukac, Helv. Chim. Acta, 73 (1990) 868-873.

[3] X. Hu, J. Mao, Y. Sun, H. Chen, H. Li, Catal. Comm., 10 (2009) 1908-1912. 
[4] J.Y. Mao, X.B. Hu, H. Li, Y. Sun, C.M. Wang, Z.R. Chen, Green Chem., 10 (2008) 827-831.

[5] A. Constantini, M. Dromard, M. Jouffret, B. Brossard, J. Varagnat, J. Mol. Catal., 7 (1980) 89-97.

[6] K. Chen, Y. Sun, C. Wang, J. Yao, Z. Chen, H. Li, Phys Chem Chem Phys, 14 (2012) 12141-12146.

[7] S. Halligudi, N. Raj, S. Deshpande, S. Gopinathan, J. Mol. Catal. A. Chem., 157 (2000) 9-14.

[8] C. Wang, G. Wang, J. Mao, Z. Yao, H. Li, Catal. Comm., 11 (2010) 758-762.

[9] L. Chen, R. Tang, Z. Li, S. Liang, Bull. Korean Chem. Soc., 33 (2012) 459-463.

[10] J. Bao, L.C.R. Tang, L. Cao, S. Liang, J. Central South Univ., 19 (2012) 2755-2759.

[11] D. Kishore, A. Rodrigues, Appl. Catal. a-Gen., 345 (2008) 104-111.

[12] E. Murphy, A. Baiker, J. Mol. Catal. A Chem., 179 (2002) 233-241.

[13] J. Zhang, C. Che, Chem. A Eur J., 11 (2005) 3899-3914.

[14] T. Joseph, S. Halligudi, C. Satyanarayan, D. Sawant, S. Gopinathan, J. Mol. Catal. A Chem., 168 (2001) 87-97.

[15] R.D. Jones, D.A. Summerville, F. Basolo, Chem. Rev., 79 (1979) 139-179.

[16] G.K. Baio Ferreira, K.A. Dias de Freitas Castro, G.S. Machado, R.R. Ribeiro, K.J. Ciuffi, G.P. Ricci, J.A. Marques, S. Nakagaki,

J. Mol. Catal. a-Chem., 378 (2013) 263-272.

[17] R. De Paula, I.C.M.S. Santos, M.M.Q. Simoes, M.G.P.M.S. Neves, J.A.S. Cavaleiro, J. Mol. Catal. a-Chem., 404 (2015) 156166.

[18] S. Banfi, A. Manfredi, F. Montanari, G. Pozzi, S. Quici, J. Mol. Catal. a-Chem., 113 (1996) 77-86.

[19] W. Liu, J.T. Groves, J. Am. Chem. Soc., 132 (2010) 12847-12849.

[20] N. Ito, T. Etoh, H. Hagiwara, M. Kato, Synthesis-Stuttgart (1997) 153.

[21] J. Mao, N. Li, H. Li, X. Hu, j. Mol. Catal. A. Chem., 258 (2006) 178-184.

[22] T. Huang, X. Wu, W.W. Weare, R.D. Sommer, Eur. J. Inorg. Chem., 33 (2014) 5662-5674.

[23] B. Delley, J. Chem. Phys., 92 (1990) 508-517. 
[24] B. Delley, J. Chem. Phys., 113 (2000) 7756-7764.

[25] J.P. Perdew, K. Burke, M. Ernzerhof, Phys. Rev. Lett., 77 (1996) 3865-3868.

[26] M. Weinert, J.W. Davenport, Phys. Rev. B, 45 (1992) 13709-13712.

[27] B. Delley, , Elsevier, Seminario Politzer eds., (1995).

[28] M.C. Durrant, Dalton Trans., 43 (2014) 9754-9765.

[29] P.M. Panchmatia, M.E. Ali, B. Sanyal, P.M. Oppeneer, J. Phys. Chem. A, 114 (2010) 13381-13387.

[30] J. Qin, R. Perera, L.L. Lovelace, J.H. Dawson, L. Lebioda, Biochemistry, 45 (2006) 3170-3177.

[31] T.Y. Dong, P.H. Ho, C.H. Cheng, Y. Wang, J. Organomet. Chem., 601 (2000) 253-258.

[32] J. Baker, A. Kessi, B. Delley, J. Chem. Phys., 105 (1996) 192-212.

[33] B. Delley, Molecular Simulation, 32 (2006) 117-123.

[34] A. Klamt, G. Schüürmann, J. Chem. Soc., Perkin Trans, 2 (1993) 799-805.

[35] B. Delley, J. Phys.-Cond. Mat., 22 (2010).

[36] M. Aydin, Vib. Spec., 68 (2013) 141-152.

[37] T. Gozet, L. Huynh, D.K. Bohme, J. Mass Spec., 45 (2010) 35-42.

[38] B.M. Hoffman, T. Szymanski, T.G. Brown, F. Basolo, J. Am. Chem. Soc., 100 (1978) 7253-7259.

[39] B.M. Hoffman, C.J. Weschler, F. Basolo, J. Am. Chem. Soc., 98 (1976) 5473-5482.

[40] S. Cai, T.K. Shokhireva, D.L. Lichtenberger, F.A. Walker, Inorg. Chem., 45 (2006) 3519-3531.

[41] H.Y. Chen, H.B. Ji, X.T. Zhou, J.C. Xu, L.F. Wang, Catal. Comm., 10 (2009) 828-832.

[42] L.J. Boucher, H.K. Garber, Inorg. Chem., 9 (1970) 2644-\&.

[43] W.R. Scheidt, M.G. Finnegan, Acta Crystallogr. C-Crystal Struct. Comm., 45 (1989) 1214-1216.

[44] B.S. Cheng, W.R. Scheidt, Acta Crystallogr. C-Cryst. Struct. Comm., 52 (1996) 361-363.

[45] D.A. Summerville, R.D. Jones, B.M. Hoffman, F. Basolo, J. Am. Chem. Soc., 99 (1977) 8195-8202. 
[46] J. Zhao, J. Moretto, P.D. Le, S. Franzen, J. Phys. Chem. B, 119 (2015), 2827-2838.

[47] S. Franzen, Proc. Natl. Acad. Sci. U. S. A., 99 (2002) 16754-16759.

[48] S. Franzen, K. Fritsch, S.H. Brewer, J. Phys. Chem. B, 106 (2002) 11641-11646.

[49] S. Franzen, J. Am. Chem. Soc., 124 (2002) 13271-13281.

[50] S. Franzen, J. Am. Chem. Soc., 123 (2001) 12578-12589.

[51] K. Fujiwara, H. Watari, Anal. Sci. , 20 (2004) 369-372.

[52] M. Beyrhouty, A.B. Sorokin, S. Daniele, L.G. Hubert-Pfalzgraf, New. J. Chem. , 29 (2005) 1245-1248.

[53] C.-M. Che, V.K.-Y. Lo, C.-Y. Zhou, J.-S. Huang, Chem. Soc. Rev., 40 (2011) 1950-1975.

[54] S. Nakagaki, G.K. Baio Ferreira, G.M. Ucoski, K.A. Dias de Freitas Castro, Molecules, 18 (2013) 7279-7308.

[55] M.M.Q. Simoes, C.M.B. Neves, S.M.G. Pires, M.G.P.M.S. Neves, J.A.S. Cavaleiro, Pure Appl. Chem., 85 (2013) $1671-1681$.

[56] C. Zhuang, J. Liu, W. Dai, Z. Wu, Y. Wang, S. Gao, Prog. Chem., 26 (2014) 277-292. 
Table 1. Effect of Time and Various Metalloporphyrin Catalysts on the Selectivity of the Oxidation of $\beta$-IP

\begin{tabular}{|c|c|c|c|c|c|c|}
\hline \multirow[t]{2}{*}{ Entry } & \multirow[t]{2}{*}{ Catalysis } & \multirow[t]{2}{*}{ Time(hr) } & \multicolumn{3}{|c|}{ Selectivity\% } & \multirow{2}{*}{$\begin{array}{l}\text { Molar ratio } \\
(\text { Catalyst/ } \beta \text {-IP)*100 }\end{array}$} \\
\hline & & & $\alpha$-IP & KIP & Side Product & \\
\hline 1 & CoTPP & 1 & 18 & 77 & 5 & 0.022 \\
\hline 2 & CoTPP & 4 & 13 & 85 & 2 & 0.022 \\
\hline 3 & CoTPP & 7 & 17 & 81 & 2 & 0.022 \\
\hline 4 & FeTPP & 1 & 6 & 89 & 5 & 0.021 \\
\hline 5 & FeTPP & 4 & 7 & 89 & 4 & 0.021 \\
\hline 6 & FeTPP & 7 & 13 & 86 & 1 & 0.021 \\
\hline 7 & CrTPP & 1 & 17 & 71 & 12 & 0.021 \\
\hline 8 & CrTPP & 4 & 17 & 77 & 6 & 0.021 \\
\hline 9 & CrTPP & 7 & 24 & 72 & 4 & 0.021 \\
\hline 10 & CuTPP & 1 & 14 & 81 & 5 & 0.011 \\
\hline 11 & CuTPP & 4 & 10 & 87 & 3 & 0.011 \\
\hline 12 & CuTPP & 7 & 15 & 83 & 2 & 0.011 \\
\hline 13 & MnTPP & 1 & 14 & 79 & 7 & 0.021 \\
\hline 14 & MnTPP & 4 & 5 & 93 & 2 & 0.021 \\
\hline 15 & MnTPP & 7 & 5 & 94 & 1 & 0.021 \\
\hline 16 & Control & 1 & 18 & 71 & 11 & 0.00 \\
\hline 17 & Control & 4 & 15 & 79 & 6 & 0.00 \\
\hline 18 & Control & 7 & 21 & 75 & 4 & 0.00 \\
\hline
\end{tabular}


Table 2. Calculated metal-ligand bond lengths and ligation energies for $\beta-\mathrm{IP}, \mathrm{CH}_{3} \mathrm{COO}^{-}$and pyridine bound to MnTPP. The energies are given in units of kcal/mol.a

\begin{tabular}{|l|l|l|l|l|l|l|}
\hline Molecule & ${\mathrm{M}-\mathrm{O}^{\mathrm{a}}}^{-}$ & ${\mathrm{M}-\mathrm{O}^{\mathrm{b}}}^{\mathrm{b}}$ & $\mathrm{M}-\mathrm{N}$ & $\Delta \mathrm{E}(\beta-\mathrm{IP})$ & $\Delta \mathrm{E}\left(\mathrm{CH}_{3} \mathrm{COO}^{-}\right)$ & $\Delta \mathrm{E}(\mathrm{Pyr})$ \\
\hline MnTPP$\left(\mathrm{CH}_{3} \mathrm{COO}^{-}\right)$ & --- & 1.86 & --- & --- & --- & --- \\
\hline MnTPP$(\mathrm{Pyr})\left(\mathrm{CH}_{3} \mathrm{COO}\right)$ & --- & 1.89 & 2.16 & --- & -13.7 & -6.4 \\
\hline MnTPP $\left(\mathrm{CH}_{3} \mathrm{COO}^{-}\right) \beta-\mathrm{IP}$ & 2.24 & 1.88 & --- & -9.7 & +3.5 & --- \\
\hline MnTPP$(\mathrm{Pyr}) \beta-\mathrm{IP}$ & 2.06 & --- & 2.02 & -0.5 & --- & $-6.5---$ \\
\hline
\end{tabular}

a. $\beta$-IP b. $\mathrm{CH}_{3} \mathrm{COO}$

Table 3. The effect of temperature on the oxidation of $\beta$-IP using MnTPP after 7 hours

\begin{tabular}{llll}
\hline $\operatorname{temp}(\mathrm{C})$ & Conversion\% & \multicolumn{3}{l}{ Selectivity } \\
& & $\alpha$-IP & K-IP \\
\hline 65 & 41 & 3 & 95.8 \\
70 & 59 & 5 & 94 \\
75 & 77 & 5 & 93 \\
\hline
\end{tabular}

Experimental Conditions: 7 hour experiment, mole percent of catalyst 0.021 
Table 4. Maximum selectivity for K-IP

\begin{tabular}{lllll}
\hline Entry & Catalyst & Time $(\mathrm{h})$ & Selectivity for K-IP(\%) & Conversion to $\beta$-IP(\%) \\
1 & CoTPP & 4 & 85 & 29 \\
2 & FeTPP & 2 & 89 & 35 \\
3 & CrTPP & 4 & 84 & 29 \\
4 & CuTPP & 3 & 89 & 28 \\
5 & MnTPP & 6 & 94 & 50 \\
6 & Control & 3 & 79 & 14 \\
\hline
\end{tabular}

*Catalyst concentrations and solution preparations are identical to Table 1

Table 5. Replacement reactions involving the $\mathrm{MTPPCl}$ starting material. A comparison of four metals, $\mathrm{Cr}, \mathrm{Mn}, \mathrm{Fe}$ and $\mathrm{Co}$ is given.

\begin{tabular}{|l|r|r|r|r|}
\hline Reaction & \multicolumn{1}{l|}{ Cr } & \multicolumn{1}{l|}{ Mn } & \multicolumn{1}{l|}{ Fe } & \multicolumn{1}{l|}{ Co } \\
\hline MTPPCl + Pyr $\rightarrow$ MTPP(Pyr)Cl & -11.5 & $-0.4^{\mathrm{a}}$ & $-22^{\mathrm{a}}$ & -15 \\
\hline $\mathrm{MTPP}(\mathrm{Pyr}) \mathrm{Cl}+\mathrm{Pyr} \rightarrow \mathrm{MTPP}(\mathrm{Pyr})_{2}+\mathrm{Cl}^{-}$ & -3.4 & -6.5 & 8.1 & -5.9 \\
\hline $\mathrm{MTPPCl}+2 \mathrm{Pyr} \rightarrow \mathrm{MTPP}(\mathrm{Pyr})_{2}+\mathrm{Cl}^{-}$ & -14.9 & -6.9 & -13.9 & -20.9 \\
\hline
\end{tabular}

a. Ligand addition is a spin-crossover reaction $\mathrm{HS} \rightarrow \mathrm{LS}$. LS is $\mathrm{S}=1 / 2$ and $\mathrm{S}=1$ in $\mathrm{Fe}$ and Mn, respectively.

Table 6. Replacement reactions involving $\beta$-IP in Fe and Mn containing TPP complexes.

\begin{tabular}{|l|l|l|}
\hline Reaction & $\mathrm{Fe} / \mathrm{Cl}^{-}$ & $\mathrm{Mn} / \mathrm{Ac}^{-}$ \\
\hline $\mathrm{MTPP}(\mathrm{Pyr}) \mathrm{X}+\beta$-IP $\rightarrow$ MTPP(Pyr $) \beta$-IP $+\mathrm{X}^{-}$ & 11.6 & 13.2 \\
\hline $\mathrm{MTPP}(\mathrm{Pyr}) \mathrm{X}+\beta$-IP $\rightarrow \mathrm{MTPP}(\beta-\mathrm{IP}) \mathrm{Cl}+\mathrm{Pyr}$ & 17.7 & 15.0 \\
\hline $\mathrm{MTPP}(\mathrm{Pyr})_{2}+\beta$-IP $\rightarrow \mathrm{MTPP}(\mathrm{Pyr}) \beta-\mathrm{IP}+\mathrm{Pyr}$ & 3.5 & 12.9 \\
\hline
\end{tabular}


Table 7. Calculated metal-ligand bond lengths and ligation energies for $\beta-\mathrm{IP}, \mathrm{Cl}^{-}$and pyridine bound to $\mathrm{MTPP}$ adducts $(\mathrm{M}=\mathrm{Cr}, \mathrm{Mn}$, $\mathrm{Fe}$ and $\mathrm{Co}$ ). Energies are tabulated in $\mathrm{kcal} / \mathrm{mol}$.

\begin{tabular}{|l|l|l|l|l|l|l|}
\hline Molecule & $\mathrm{M}-\mathrm{O}$ & $\mathrm{M}-\mathrm{Cl}$ & $\mathrm{M}-\mathrm{N}$ & $\Delta \mathrm{E}(\beta-\mathrm{IP})$ & $\Delta \mathrm{E}\left(\mathrm{Cl}^{-}\right)$ & $\Delta \mathrm{E}(\mathrm{Pyr})$ \\
\hline CrTPP(Pyr) $\beta$-IP & 2.072 & --- & 2.106 & -10.5 & --- & -22.2 \\
\hline CrTPP(Pyr) 2 & --- & --- & 2.132 & --- & --- & -19.7 \\
\hline CrTPP(Pyr)Cl & --- & 2.177 & 2.288 & --- & -26.9 & -16.2 \\
\hline CrTPP(Cl) $\beta$-IP & 2.227 & 2.290 & --- & -4.5 & -26.3 & --- \\
\hline MnTPP(Pyr) $\beta$-IP & 2.104 & --- & 2.088 & -13.2 & --- & -7.5 \\
\hline MnTPP(Pyr) 2 & --- & --- & 2.107 & --- & --- & +11.9 \\
\hline MnTPP(Pyr)Cl & --- & 2.292 & 2.145 & --- & -19.4 & -16.7 \\
\hline MnTPP(Cl) $\beta-I P$ & 2.333 & 2.278 & --- & +1.6 & -18.4 & --- \\
\hline FeTPP(Pyr) $\beta$-IP & 2.223 & --- & 2.073 & -1.6 & --- & -12.3 \\
\hline FeTPP(Pyr) 2 & --- & --- & 2.073 & --- & --- & -15.4 \\
\hline FeTPP(Pyr)Cl & --- & 2.291 & 2.109 & --- & -18.4 & -7.3 \\
\hline FeTPP(Cl) $\beta-I P$ & 3.902 & 2.268 & --- & -0.5 & -22.3 & --- \\
\hline CoTPP(Pyr) $\beta-I P$ & 4.750 & --- & 2.106 & -3.0 & --- & -9.9 \\
\hline CoTPP(Pyr) 2 & --- & --- & 2.105 & --- & --- & -8.1 \\
\hline CoTPP(Pyr)Cl & --- & 2.321 & 2.143 & --- & -13.8 & $-6.7---$ \\
\hline CoTPP(Cl) $\beta-I P$ & 3.870 & 2.315 & -- & -3.4 & -18.6 & --- \\
\hline
\end{tabular}


Table 8. Relative energy of hydrogen abstraction for the two geometries on $\alpha$-IP and $\beta$-IP. The calculated values represent the energy for $\alpha$-IP or $\beta$-IP bonded to a metal center relative to the value for hydrogen abstraction for free $\alpha$-IP or $\beta$-IP. Energies are reported in $\mathrm{kcal} / \mathrm{mol}$.

\begin{tabular}{|l|l|}
\hline$(\mathrm{Fe}) \alpha-\mathrm{IP}(\mathrm{sp} 2)$ & +25.8 \\
\hline$(\mathrm{Fe}) \alpha-\mathrm{IP}(\mathrm{sp} 3)$ & -12.3 \\
\hline$(\mathrm{Fe}) \beta-\mathrm{IP}(\mathrm{sp} 2)$ & 0.0 \\
\hline$(\mathrm{Fe}) \beta-\mathrm{IP}(\mathrm{sp} 3)$ & -15.6 \\
\hline$(\mathrm{Mn}) \alpha-\mathrm{IP}(\mathrm{sp} 2)$ & -7.4 \\
\hline$(\mathrm{Mn}) \alpha-\mathrm{IP}(\mathrm{sp} 3)$ & -12.1 \\
\hline$(\mathrm{Mn}) \beta-\mathrm{IP}(\mathrm{sp} 2)$ & +10.2 \\
\hline$(\mathrm{Mn}) \beta-\mathrm{IP}(\mathrm{sp} 3)$ & -12.2 \\
\hline$(\mathrm{Cr}) \beta-\mathrm{IP}(\mathrm{sp} 2)$ & -6.9 \\
\hline$(\mathrm{Cr}) \beta-\mathrm{IP}(\mathrm{sp} 3)$ & -19.2 \\
\hline
\end{tabular}

Table 9. Rate constants for formation of product KIP and side product $\alpha$-IP at $70{ }^{\circ} \mathrm{C}$.

The values in the table are all in units of $10^{-6} \mathrm{M}^{-1} \mathrm{~s}^{-1}$.

\begin{tabular}{|l|r|r|r|r|}
\hline & \multicolumn{1}{|l|}{$\alpha$-IP } & \multicolumn{1}{l|}{$\sigma(\alpha-\mathrm{IP})$} & \multicolumn{1}{l|}{$\sigma(\mathrm{KIP})$} & \\
\hline MnTPP & 0.167 & 0.014 & 9.88 & 0.53 \\
\hline FeTPP & 1.01 & 0.16 & 12.6 & 0.50 \\
\hline CoTPP & 0.887 & 0.09 & 7.77 & 0.45 \\
\hline Blank & 0.769 & 0.16 & 5.34 & 0.29 \\
\hline
\end{tabular}




\section{Figures}
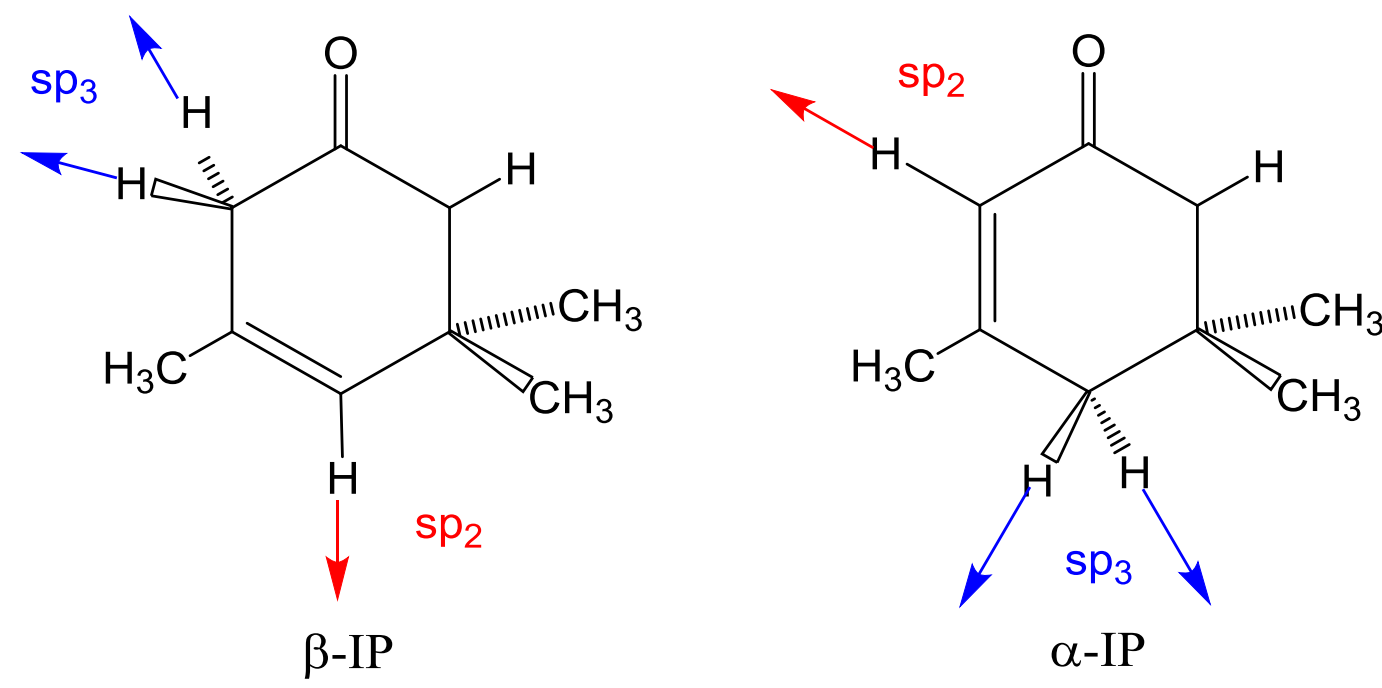

Figure 1. Structures of $\beta$-IP and $\alpha$-IP showing the hybridization of the carbon atoms from which hydrogen abstraction occurs. The sp 3 sites were considered to be energetically equivalent although they may not be sterically equivalent under reaction conditions. 


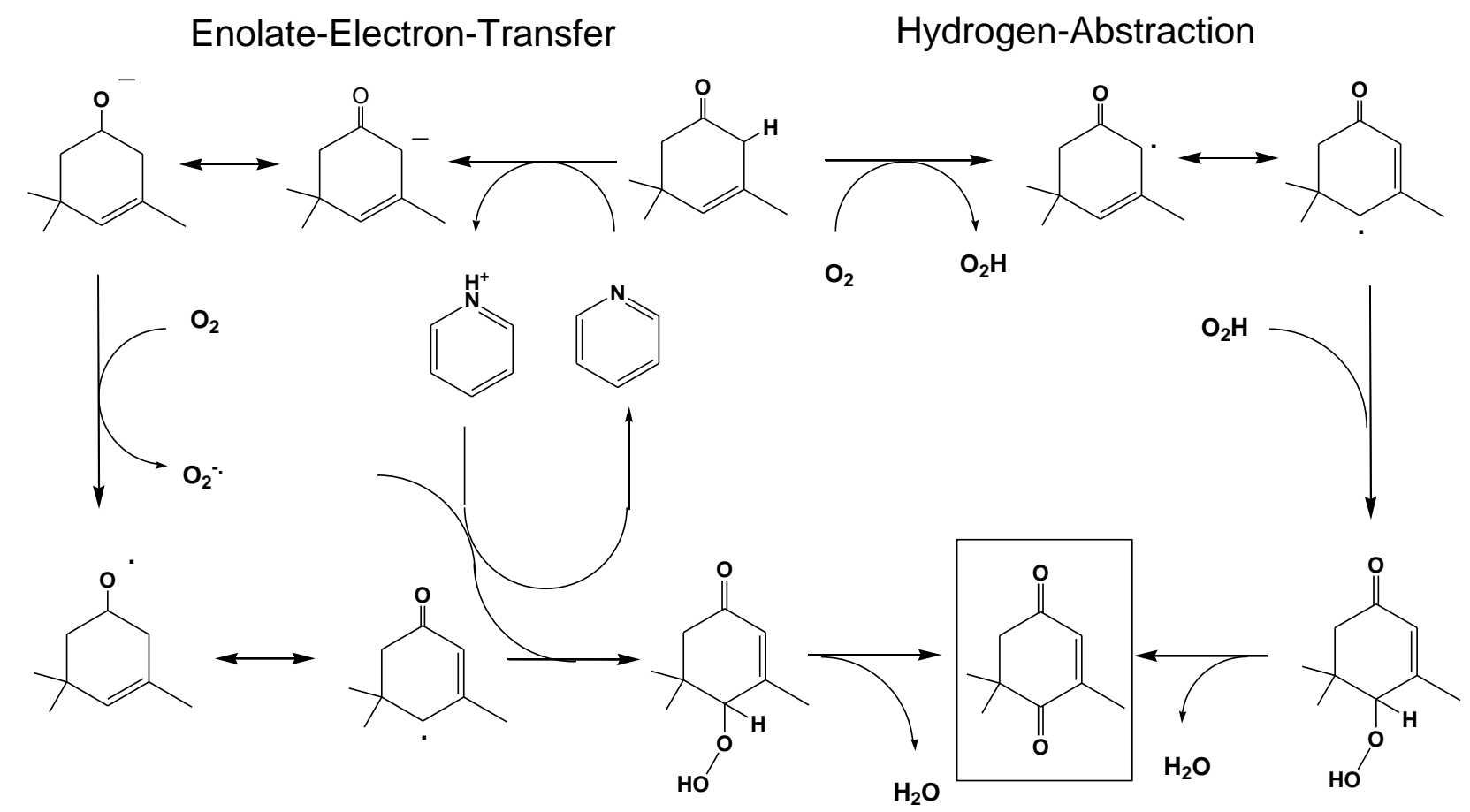

Figure 2. Two alternative mechanisms for the radical pathway in the reaction from $\beta$-IP to KIP. 

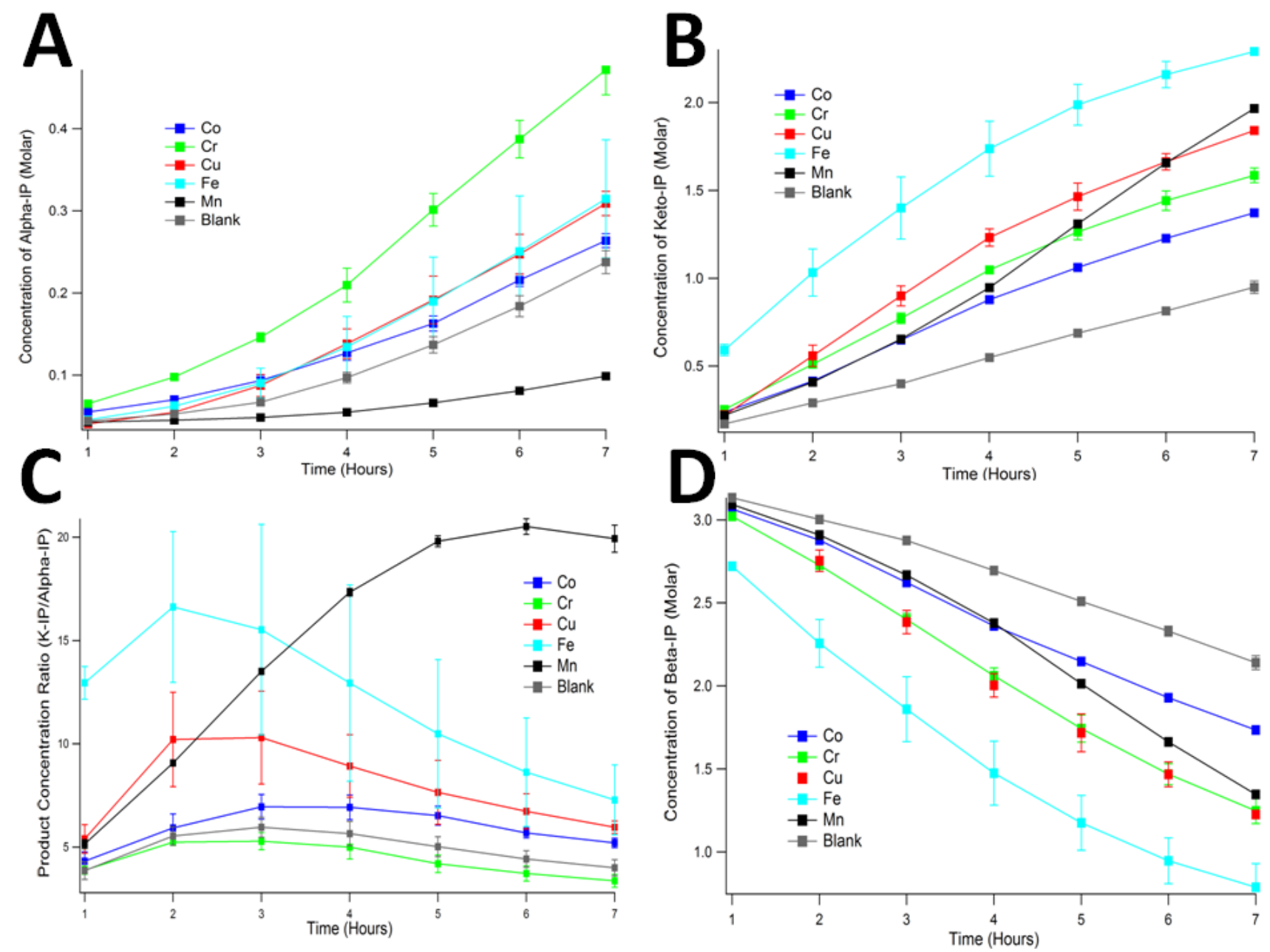

Figure 3. Time courses for reactant and product formation in the catalyzed reaction of $\beta$-IP to form KIP, with side product $\alpha$-IP. A. $\alpha$ IP production over the course of 7 hours. B. KIP production. C. Ratio of $[\mathrm{KIP}] /[\alpha-\mathrm{IP}]$ production. D. $\beta$-IP consumption. 


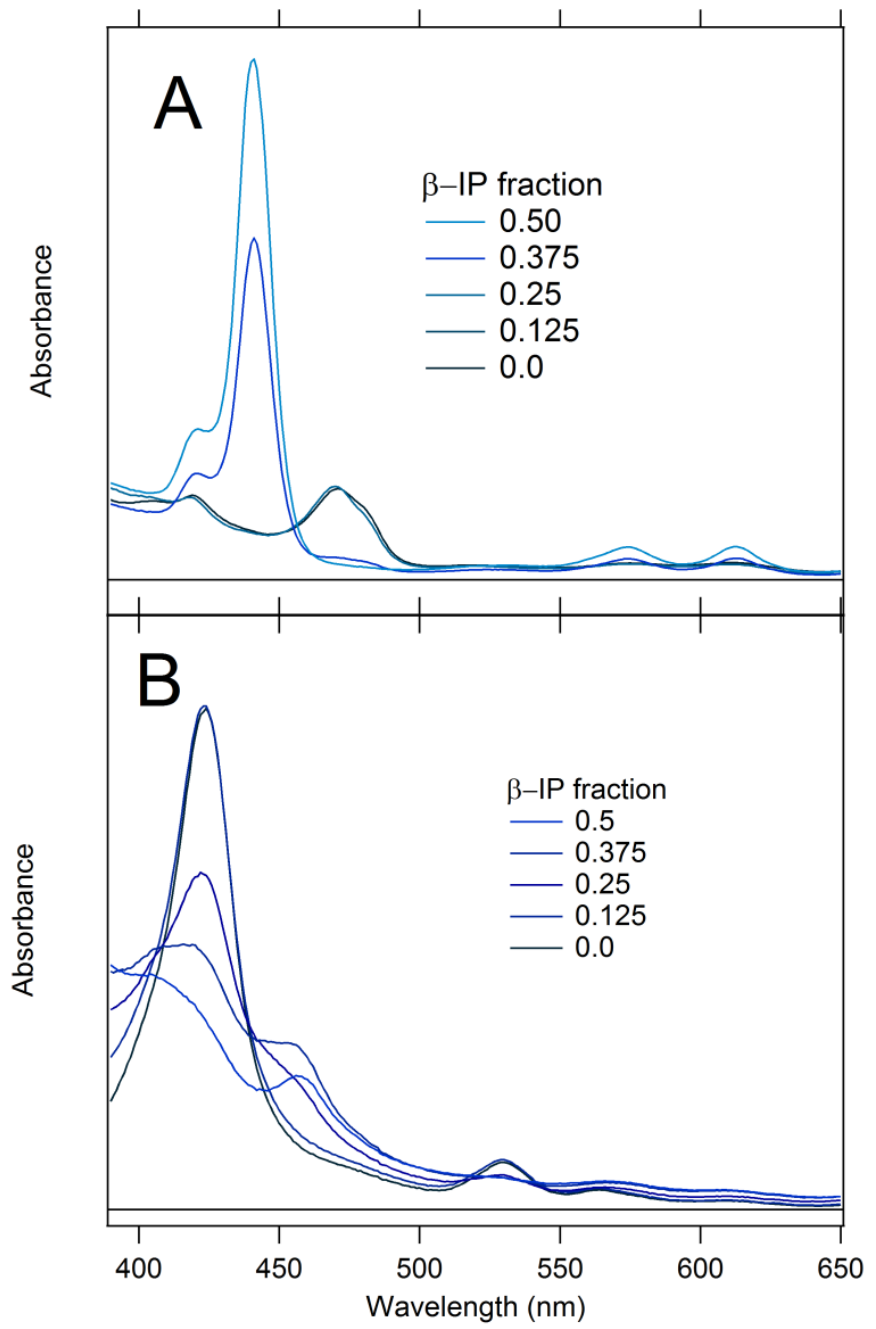

Figure 4. Absorption spectra of A.) MnTPP and B.) FeTPP in mixtures of pyridine and $\beta$-IP. 

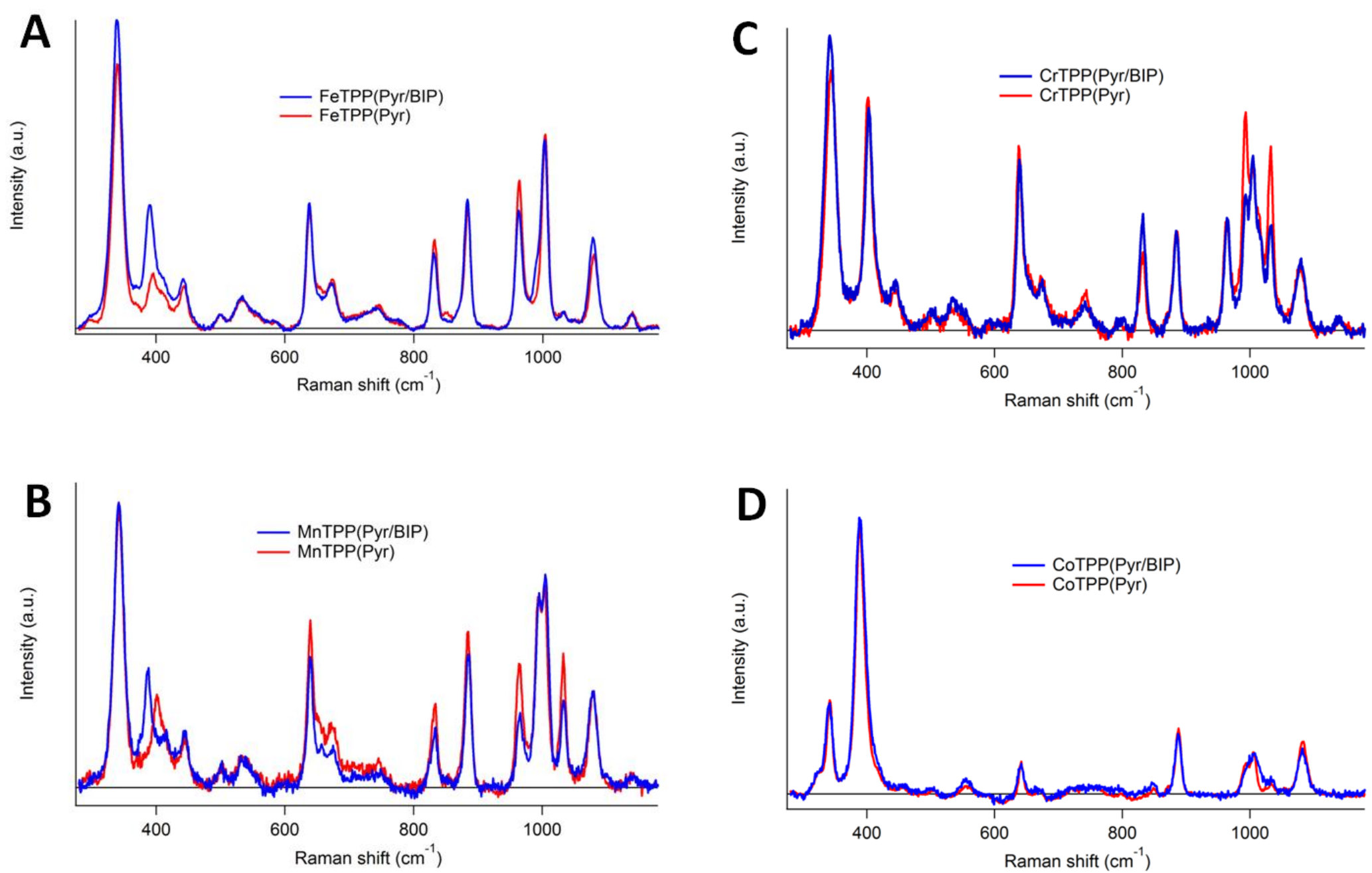

Figure 5. Resonance Raman spectra (excited at $417 \mathrm{~nm}$ ) of the MTPP species in pyridine and 0.5 volume fraction of $\beta$-IP with pyridine. A. FeTPP, B. MnTPP, C. CrTPP, D. CoTPP 


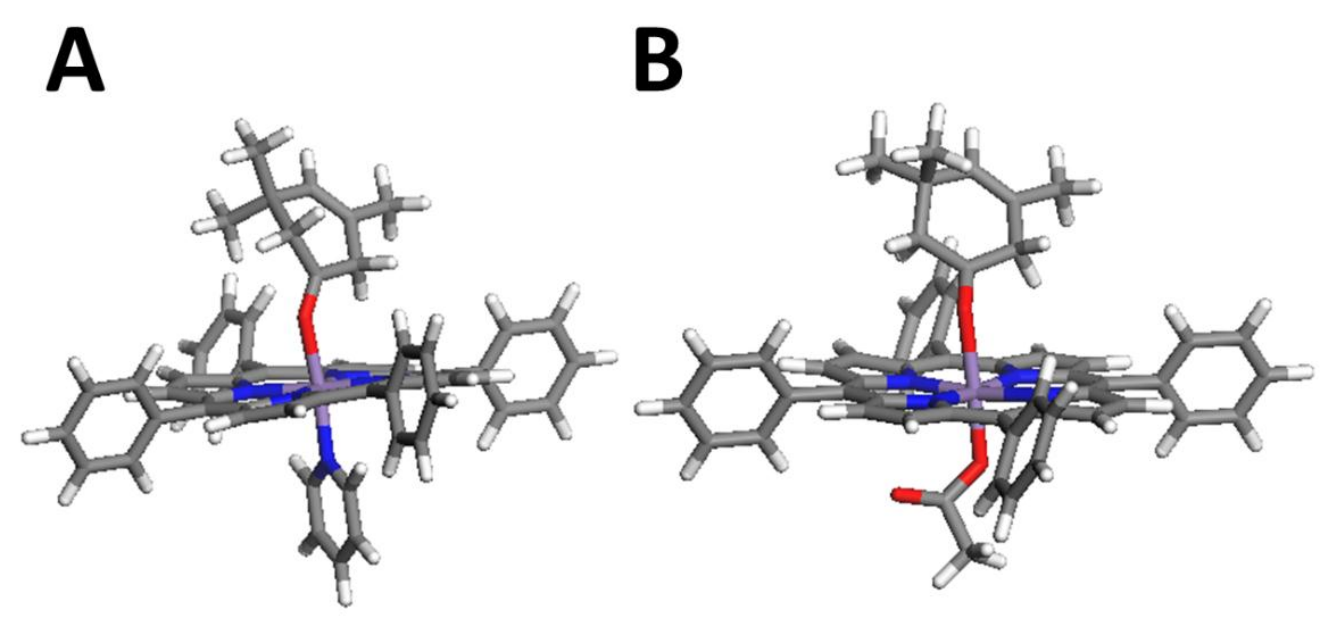

Figure 6. DFT calculated geometries of the $\beta$-IP adduct with MnTPP(Pyr) and MnTPP(Ac). 

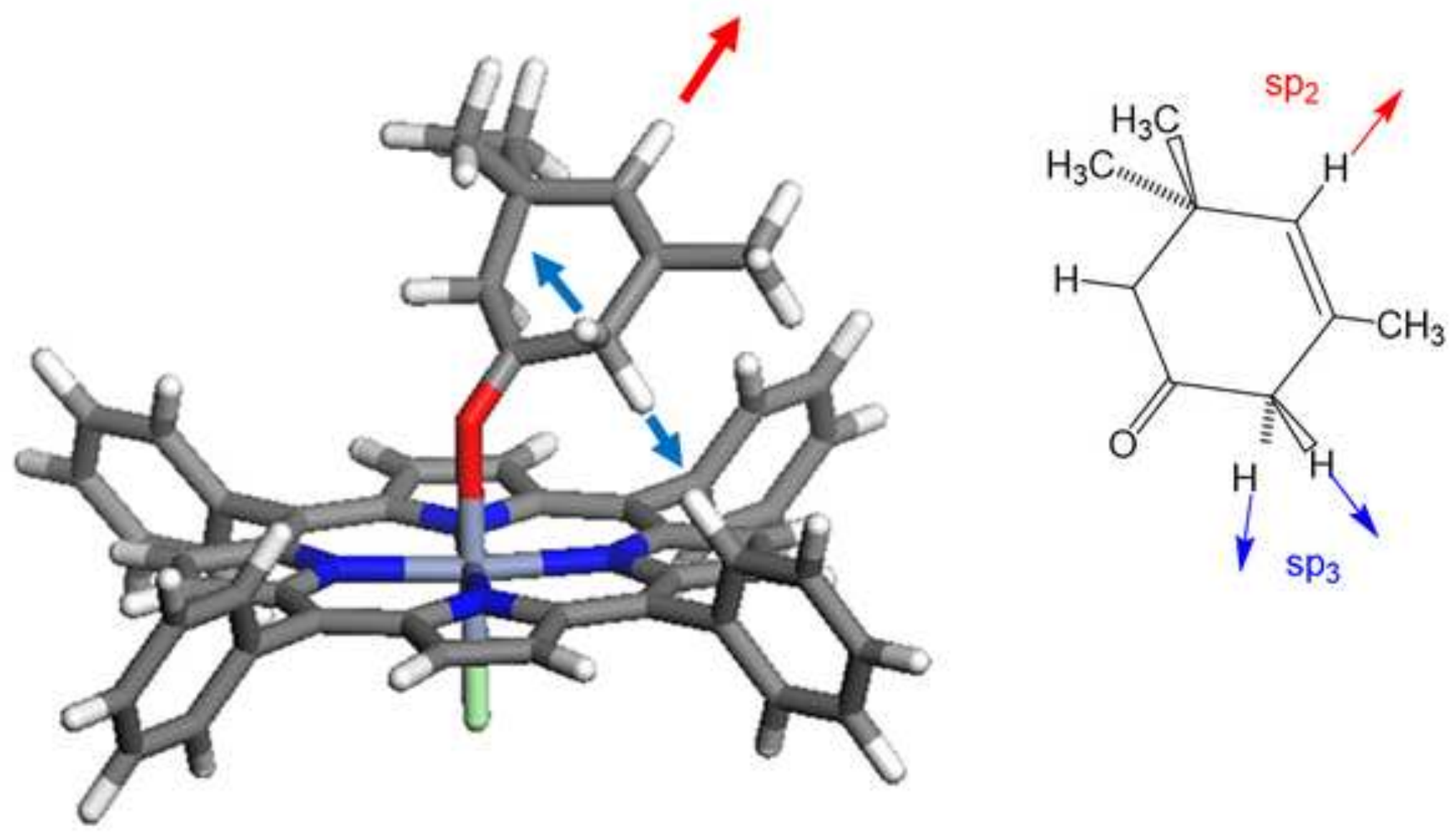